\title{
PEMBERDAYAAN MASYARAKAT TERHADAP NILAI JUAL SUMBER DAYA ALAM MELALUI INOVASI EKONOMI KREATIF PISANG NUGGET
}

\author{
Ibrahim Fajri ${ }^{1}$, Anggi Gustian, Firdha Tri Santika, Nurhasannah ${ }^{2}$ \\ ibrahim@uika-bogor.ac.id \\ Dosen Fakultas Hukum ${ }^{1}$, Mahasiswa KKN Kelompok 43 Tahun $2018^{2}$
}

\begin{abstract}
ABSTRAK
Mengelola sumber daya alam di desa gunung picung untuk menjadi sesuatu yang bernilai jual tinggi menjadi salah satu permasalahan yang umumnya dihadapi di indonesia khususnya di desa desa terpencil. Banyak orang-orang yang malas memikirkan inovasi inovasi terbaru, dampaknya karena pemikiran-pemikiran warga dipedasaan belum memiliki pemikiran modern yang sedang berkembang, terutama dalam bidang ekonomi. Membangun UMKM (Usaha Micro Kecil \& Menengah) adalah untuk menjadi salah satu sarana kegiatan masyarakat di bidang ekonomi, ekonomi kreatif merupakan alternatif suatu solusi permasalahan didalam perekonomian masyarakat pedesaan. Pisang nugget ini menjadi salah satu cara untuk dapat memanfaatkan hasil sumber daya alam yang menjadi ladang usaha masyarakat yang mempuni, di sisi lain perekonomian sangatlah berpengaruh dalam aspek sosial untuk kesejahteraan masyarakat.
\end{abstract}

Kata kunci : Pemberdayaan, Inovasi produk, UMKM.

\section{PENDAHULUAN}

\section{Latar Belakang}

Di Indonesia Sumber daya alam merupakan salah satu sumber yang dapat di jadikan mata pencaharian bagi masyarakat khusus nya yang hidup di kawasan pedesaan. Hasil-hasil perkebunan berupa sayur - mayur, buah - buahan Dan rempahrempah menjadi komoditas utama dalam membangun perekonomian masyarakat . Namun kurang nya kesadaran masyarakat dalam mengelola hasil tersebut menjadi sesuatu yang bernilai jual lebih menjadi permasalahan utama dalam pembangunan ekonomi masyarakat.

Chambers

(Zubaedi,

2013)

mengungkapkan

masyarakat adalah pemberdayaan sebuah konsep pembangunan ekonomi yang merangkum nilai-nilai sosial. Konsep ini mencerminkan paradigma baru pembangunan yang bersifat people-centered, participatory, empowering and sustainable. Pemberdayaan masyarakat sebagai sebuah strategi, sekarang telah banyak diterima, bahkan telah berkembang dalam berbagai literatur di dunia barat. Pemberdayaan masyarakat adalah sebuah konsep pembangunan ekonomi yang merangkum nilai-nilai sosial.

UMKM (Usaha Mikro Kecil \& Menengah) adalah suatu wadah atau sarana bagi masyarakat untuk mengelola sumber daya alam menjadi suatu mata pencaharian. UMKM memiliki peran strategis dalam pembangunan ekonomi nasional terbukti saat indonesia mengalami krisis yang 
terjadi dalam beberapa waktu lalu. Usaha Mikro Kecil Menengah (UMKM) lebih tangguh dalam menghadapi realita tersebut,sedangkan usaha yang berskala besar mengalami stagnasi bahkan berhenti aktifitasnya

Saat ini, ekonomi kreatif mampu hadir sebagai salah satu jenis usaha yang menjadi komoditas di perekonomian Indonesia. Industri ekonomi kreatif ini merupakan hasil dari pemanfaatan kreativitas, keterampilan, serta bakat individu untuk menciptakan kesejahteraan serta lapangan pekerjaan dengan menghasilkan dan mengeksploitasi daya kreasi dan daya cipta individu. Sehingga mampu mengurangi angka kemiskinan dan juga angka pengangguran di Indonesia. Oleh karena itu, mengembangkan UMKM menjadi salah satu solusi yang mahasiswa hadirkan di masyarakat. Kami berinisiatif untuk membuat pelatihan bagi masyarakat dalam hal pengelola an sumber daya alam untuk menjadi sesuatu yang lebih bernilai. Dalam hal ini kami memanfaatkan bahan baku pisang untum diolah menjadi jenis makanan yang lebih modern dan kreatif yaitu Pisang Nugget.

\section{Geografis}

Desa Gunung Picung salah satu desa diwilayah Kecamatan Pamijahan Kabupaten Bogor dan merupakan ibu kota Kecamatan Pamijahan dengan luas : 526.922.3 Ha, diatas permukaan laut 600 $920 \mathrm{M}$, dan tinggi curah hujan 2800 - 3400 M3 yang terbagi dalam 4 dusun $12 \mathrm{RW}$ dan 48 RT.

Batas Desa Gunung Picung adalah sebagai berikut:

Sebelah Utara :Desa Gunung Menyan.

Sebelah Timur :Desa Gunung Bunder I dan II / Kali Ciaruteun.

Sebelah Selatan :Kabupaten Sukabumi.
Sebelah Barat : Kali Cigamea / Desa Gunung Sari.

Pemanfaatan lahan/penggunaan tanah di Desa Gunung Picung adalah sebagai berikut:

1. Perumahan / pemukiman dan pekarangan: $159.030 \mathrm{Ha}$

2. Sawah: $225 \mathrm{Ha}$

3. Ladang / perkebunan rakyat : $125 \mathrm{Ha}$

4. Jalan: $11.042 \mathrm{Ha}$

5. Pemakaman / kuburan: $4.5 \mathrm{Ha}$

6. Perkantoran: $855 \mathrm{Ha}$

7. Lapangan olahraga: $1 \mathrm{Ha}$

\section{Kondisi Monografi}

Jumlah penduduk Desa Gunung Picung sampai dengan Bulan Desember Tahun 2016 adalah sebanyak 13.076 jiwa, antara lain:

1. Laki - laki: 6.229 Jiwa

2. Perempuan: 6.243 Jiwa

3. Jumlah KK: 3.200 Jiwa

Dengan kepadatan penduduk : $5 \mathrm{KK} / \mathrm{Km}$

Mengenai penduduk berdasarkan agama, sebagai berikut:

1. Islam : 13.070 orang

2. Kristen: 3 orang

3. Protestan: 3 orang

4. Hindu : -

5. Budha :-

6. Konghuchu: -

Keadaan mata pencaharian penduduk Desa Gunung Picung adalah sebagai berikut:

1. Tani / buruh tani : 2.483 orang

2. Petani pemilik : 215 orang

3. Pedagang : 900 orang

4. Pegawai Negeri Sipil: 95 orang

5. TNI / POLRI : 18 orang

6. Pensiunan / purnawirawan : 32 orang

7. Swasta : 552 orang 
8. Buruh pabrik : 600 orang

9. Pengrajin : 56 orang

10. Tukang bangunan: 120 orang

11. Penjahit :50 orang

12. Tukang las : $: 5$ orang

13. Tukang ojeg : 300 orang

14. Bengkel :21 orang

15. Sopir agkutan : 145 orang

16. Lain - lain : 50 orang

Adapun tingkat pendidikan penduduk

Desa Gunung Picung adalah sebagai berikut:

1. Tidak tamat SD: 4.755 orang

2. Tamar SD/sederajat: 3.840 orang

3. Tamat SLTP / sederajat: 2.025 orang

4. Tamat SLTA / sederajat: 1.456 orang

5. Tamat Akademi : 89 orang

6. S $1 \quad$ : 62 orang

7. S 2 : 12 orang

8. S 3 :2 orang

\section{Potensi Sumber Daya dan Bahan Baku}

Desa Gunung Picung kecamatan Pamijahan Kabupaten Bogor memiliki kekayaan alam berupa hasil pangan yang melimpah salah satunya adalah Buah Pisang, Pisang ini diolah menjadi pisang nugget yang memiliki nilai jual lebih tinggi dibanding pisang yang belum diolah.

Proses pembuatan nya yaitu pisang yang dihaluskan dan dicampur dengan susu kental manis lalu dicampurkan dalam adonan tepung,gula,dan garam. Setelah itu dikukus selama 15 menit lalu dibiarkan beberapa saat lalu dibentuk sesuai selera, lalu dibalut dengan telur dan tepung roti dan digoreng. Agar lebih menarik bisa diberi topping sesuai selera.

\section{Peluang Pasar}

Melihat situasi diwilayah tersebut sasaran untuk makanan (kuliner) sangatlah strategis maka munculnya daya inovasi dan kreatifitas dalam bidang ekonomi dapat menjadi peluang melakukan suatu kegiatan berdagang, pisang nugget memiliki potensi nilai jual lebih tinggi dari makanan lainnya. Dengan ini kami harap bisa memajukan suatu kegiatan bidang usaha UMKM yang berdampak pada kesejahteraan masyarakat.

\section{METODE PENGABDIAN}

Tahap awal pembuatan pisang nugget

1. Memanfaatkan pisang yang sudah sangat matang, kemudian dikupas,lalu dihaluskan dengan cara ditumbuk dengan dicampur susu kental manis hingga merata.

2. Mencampurkan adonan pisang yang sudah halus dengan tepung yang sudah dicampur gula dan garam.

3. Mengukus seluruh adonan selama 15 menit

4. Cetak adonan yang sudah dikukus sesuaiselera

5. Setelah dicetak, lalu balut dengan telur yang sudah dikocok lepas

6. Ditaburi tepung roti hingga merata

7. Bahan pisang nugget yang sudah jadi tersebut dapat bertahan selama 1bulan jika disimpan dilemari es (Freezer)

\section{Tahap akhir}

1. Goreng pisang nugget yang sudah ditaburi tepung roti sampai berubah warna menjadi coklat keemasan.

2. agar lebih menarik pisang nugget bisa diberi topping sesuai selera

\section{ANGGARAN PISANG NUGGET}

\begin{tabular}{|l|l|}
\hline Pisang & Rp. 15.000 \\
\hline Gula @ $1 / 2 \mathrm{Kg}$ & Rp. 7.000 \\
\hline Tepung @ $1 \mathrm{Kg}$ & Rp. 10.000 \\
\hline Telur @ $1 / 2 \mathrm{Kg}$ & Rp. 12.000 \\
\hline
\end{tabular}




\begin{tabular}{|l|l|} 
Susu @ 6 pcs & Rp. 12.000 \\
\hline Tepung roti @ 1/2Kg & Rp. 10.000 \\
\hline mentega & Rp. 7.000 \\
\hline coklat Blok & Rp. 12.000 \\
\hline Keju & Rp. 15.000 \\
\hline & \\
TOTAL & Rp. 100.000 \\
\hline
\end{tabular}

\section{HASIL DAN PEMBAHASAN}

Kegiatan Pelatihan Membuat Pisang Nugget dilaksanakan pada hari Rabu tanggal 15 Agustus 2018 bertempat di kediaman ketua RT 01 RW 04 Kp. Pasar Ahad Ds. Gunung Picung Kec. Pamijahan Kab. Bogor. Selama sekitar dua jam dari Jam 09.00 s/d 11.00 .
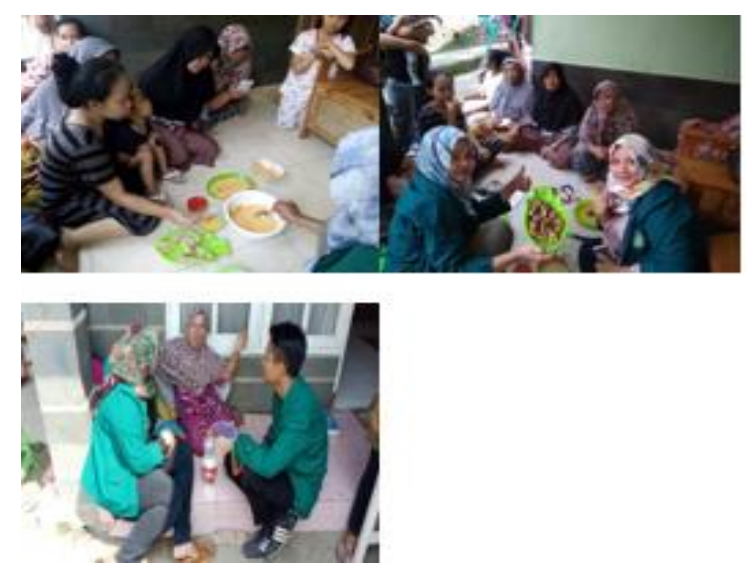

\section{KESIMPULAN}

1. Menciptakan produk makanan dari pisang yang memiki nilai jual standar

2. Mengedukasi masyarakat untuk lebih kreatif dalam mengelola bahan pangan

\section{REFERENSI}

Adler Haymans Manurung, Modal Untuk Bisnis Ukm, Jakarta, 2008, PT Kompas Media Nusantara. hlm 8.

Oki Dwi Saputra, Heryanto Susilo. (2016). Pemberdayaan Masyarakat Melalui Usaha Kecil dan Menengah (UKM) Studi Kasus di Sentra Industri Tepung Tapioka Desa Pogalan, Kecamatan Pogalan,. J+Plus, Volume II.

Rahmat Rosadi, Eska Perdana Prasetya. (2018). Pelaksanaan KKN Tematik Terintegritas . Bogor: Uika Press.

Timotiuslubech, Samuelanggak, Yosafat, Yosuakurniawan, Makanan Sehat Pisang Nugget, 2017,Universitas Kristen Maranatha, Bandung.

Z Heflin Frince. 2004,Kewirausahaan dan Inovasi Bisnis. Darussalam.: Yogyakarta. 